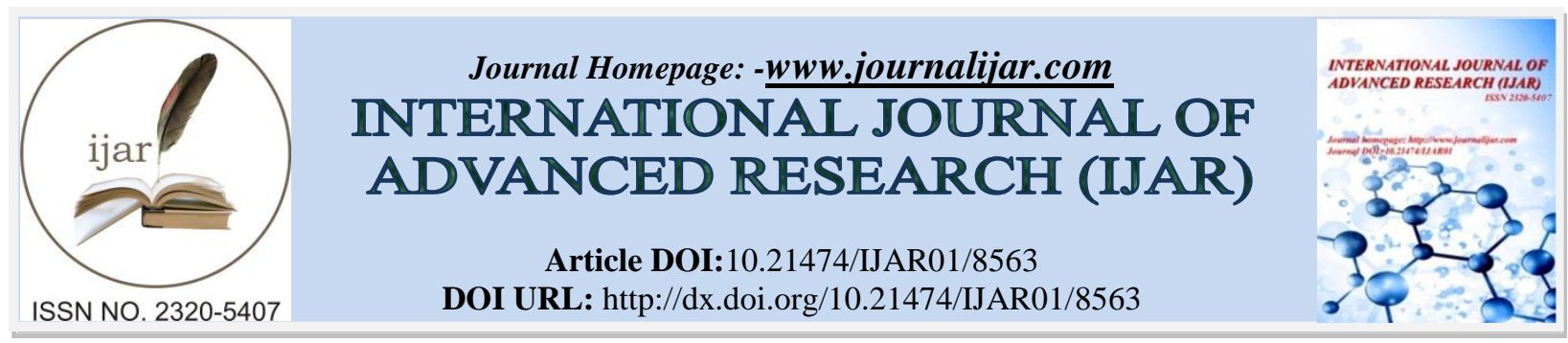

RESEARCH ARTICLE

\title{
HEMOPHAGOCYTIC LYMPHOHISTIOCYTOSIS: DON'T FORGET DISSEMINATED MYCOBACTERIUM TUBERCULOSIS: A PEDIATRIC CASE.
}

\author{
Bellamlih Habib, Bouimetarhan Lamiae, El farouki Aymane, Zouaki Zakaria and Dafiri Rachida. \\ Department of Radiology,Mohammed V-Souissi University, Rabat, Morocco.
}

\section{Manuscript Info}

Manuscript History

Received: 14 December 2018

Final Accepted: 16 January 2019

Published: February 2019

Key words:-

Hemophagocyticlymphohistiocytosis,

Mycobacterium tuberculosis,

Antitubercular therapy.

\section{Abstract}

Hemophagocytic lymphohistiocytosis is an uncommun and potentially fatal disease. It is a hyperinflammatory syndrome characterized by excessive macrophage and T-cell activation as well as impairment of the ability of natural killer cells and cytotoxic $\mathrm{T}$ lymphocytes to kill the target cells. It is either primary or secondary and it is linked to various etiologies especially infections. It may rarely complicate the clinical course of disseminated Mycobacterium tuberculosis. Its therapeutic management is often difficult and not codified in the absence of largescale controlled studies. We report a pediatric case of secondary hemophagocytic lymphohistiocytosis due to disseminated Mycobacterium tuberculosis in an immunocompetent child with a favorable outcome following early initiation of antitubercular therapy.

Copy Right, IJAR, 2019,. All rights reserved.

\section{Introduction:-}

Hemophagocytic lymphohistiocytosis (HLH) is a rare and potentially fatal syndrome of exacerbated but ineffective inflammatory responses. [1]

Primary or familial HLH appears to have a genetic basis, whereas secondary or acquired HLH may be associated to various etiologies such as infections, hematological malignancies, or autoimmune disorders $[2,3]$. To be originated from tuberculosis is unusual. In that case, the diagnosis is difficult and its treatment is not well established. [4] In this manuscript, we describe a 4 years old child, with tuberculosis-associated HLH with a favorable outcome following early initiation of antitubercular therapy.

\section{Case report:}

A 4-year-old male child, with no history, was referred to our hospital for persistent fever. The general physical examination revealed that the patient was febrile (oral temperature: $38,8^{\circ} \mathrm{C}$ ) with significant conjunctival pallor, scleral icterus, bilateral subcentimeter cervical and axillary lymphadenopathy. Abdominal examination showed an isolated hepatosplenomegalia.The neurological examination of the child revealed a rigidity of the neck with the sign of Kernig. In addition, plantar reflexes suggested an extensor response and deep tendon reflexes an exaggerated response.

Routine laboratory evaluation showed normocytic anemia (hemoglobin: $78 \mathrm{~g} / \mathrm{L}$ ), leukopenia [leukocyte count: $1.7 \times$ $10^{9} / \mathrm{L}$ ], total platelet count: $160 \times 10^{9} / \mathrm{L}$, total bilirubin: $3 \mathrm{mg} / \mathrm{dL}$, raised liver transaminases ( $>3$ times the upper limit of normal) and prolonged prothrombin time.

Corresponding Author:-Bellamlih Habib.

Address:-Department of Radiology, Mohammed V-Souissi University, Rabat, Morocco. 
Biochemical evaluation revealed hyperferritinemia $(1509 \mathrm{ng} / \mathrm{mL})$, raised lactate dehydrogenase (709 IU/L), hypoalbuminemia $(2.3 \mathrm{~g} / \mathrm{dL})$, and hyponatremia $(124 \mathrm{meq} / \mathrm{L})$.

The cerebral CT revealed hydrocephalus associated with basal meningeal enhancement (fig1).

The thoraco-abdominal CT showed a multiple mediastinal and abdominal adenopathies with necrotic centers. Also, a hepatosplenomegaly containing hypodense nodules and moderate ascites were found (fig 2).

Cytobacteriological examination of the urine, haemocultures, chlamydia, mycoplasma, legionella, leptospirosis, HIV, EBV, CMV, HCV, HBV serology were negative.

Immune balance (antinuclear factors, ANCA, electrophoresis of proteins with weight immunoglobulins) shows only a polyclonal increase of immunoglobulins with $\mathrm{IgG}$ at $15 \mathrm{~g} / \mathrm{L}$.

A bone marrow aspiration and trephine biopsy were performed, which showed hemophagocytosis associated with disseminated medullary granulomas epithelioid-giant cell with caseous necrosis. The diagnosis of HLH secondary to hematopoietic and disseminated tuberculosis was established

The patient was managed with broad-spectrum intravenous antibiotics and supportive measures. Furthermore, he was put under antituberculosis therapy (ATT) with isoniazid, rifampicin, pyrazinamide, and ethambutol. He responded to ATT and was discharged in a stable condition on day 15 post admission with hemoglobin of $88 \mathrm{~g} / \mathrm{L}$, and platelet count of $180 \times 10^{9} / \mathrm{L}$. On two-month follow-up, he was found to be responding well to ATT.

\section{Discussion:-}

The HLH is a particular clinicopathological entity characterized by excessive activation of macrophages and cells, as well as the ability of Natural Killer (NK) cells and cytotoxic T lymphocytes to attack target cells [5]. Since its identification, several names are used [5,6].

The disease mainly affects children, especially primary forms, but can occur at any age.

Its incidence is probably underestimated: 0.6 to 1 case / 500000 inhabitants. Approximately 2197 were reported between 1975 and 2011. Half of cases were from Japan [7].

The physiopathology is still poorly known today; the hypersecretion of cytokines (including TNF-alpha, IFNgamma, IL-6) by activated macrophages is probably responsible for clinical and biological manifestations. The activation of these macrophages seems partly due to the secretion of stimulatory cytokines by T lymphocytes CD8 and NK cells activated, having lost their cytotoxic power but not their power to produce cytokines. Because of this ineffective activation of lymphocytes, the causative agent of HLH may persist as well as macrophages. [8]

In addition, the secretion of inhibitory cytokines could lead to depression of granulocyte precursors and erythropoietic in the bone marrow.

There is primary and secondary forms. The causes of secondary form are dominated by infection (50.4\%). Bacterial infections are reported in $9 \%$ of cases of which $38 \%$ are due to tuberculosis [7].

The diagnosis is established by fulfilling one of the following HLH 2004 criteria:

1. Positive family history or molecular diagnosis consistent with HLH (mutations of PRF, SAP, or Munc13-4 genes),

2. Any five out of the following eight criteria: Prolonged fever, unexplained progressive cytopenias involving at least two cell lines (hemoglobin $=90 \mathrm{~g} / \mathrm{L}$, platelet count $=100 \times \mathbf{1 0} / \mathrm{L}$, absolute neutrophil count $<1 \times 10 / \mathrm{L}$ ); splenomegaly; hyperferritinemia $(=500 \mathrm{ng} / \mathrm{mL})$; fasting hypertriglyceridemia $(=265 \mathrm{mg} / \mathrm{dL})$ or hypofibrinogenemia $(=1.5 \mathrm{~g} / \mathrm{L})$; histiocytic hemophagocytosis in bone marrow, liver, spleen, or lymph nodes without evidence of malignancy; low or absent NK cell cytotoxicity; and elevated soluble CD25 levels (=2400 $\mathrm{IU} / \mathrm{mL}$ of interleukin-2R chain). [9]

3. The diagnosis of secondary HLH is retained in front of the combination of clinical, laboratory and histopathological signs. The clinical picture is non-specific [7, 10]. 
4. Bone marrow aspiration has a sensitivity of $84 \%$ for the diagnosis of HLH [11]. It shows rich marrow infiltration by histiocytosis of a benign cytological appearance.

5. The medullary macrophages show intracytoplasmic vacuoles containing blood cellular elements or their hematopoietic precursors. The erythroblastosis is frequently observed.

6. The bone marrow biopsy is barely contributory but it may reveal hemophagocytosis with macrophage proliferation. It remains useful for the etiological diagnosis of the underlying hematological disease. The Phagocytosis may not be present initially and a second biopsy may be indicated in case of strong suspicion of HLH. Other cytological and histological tests may be informative [11].

The principle of therapeutic management of HLH is based on three simultaneous approaches. The first concerns conditioning and intensive care measures. The second approach is to determine the triggering factor and eliminate it, which may be sufficient to stop the progression of HLH [5]. The third approach is the elimination of the excessive inflammatory response. The choice of the drug depends essentially on the underlying disease, the severity of the symptoms, the response to the initial treatment and the HLH episode [5, 7].

HLH due to tuberculosis in 36 patients were listed in a literature review, characterized by the presence of the underlying comorbidities and the predominance of extra-thoracic tuberculosis [4]; half of patients were immunocompromised (kidney transplant, cancer, HIV). The same clinical signs were present (fever, hepatosplenomegaly). Eighty percent of the cases were disseminated tuberculosis. The mortality was about 50\%. All patients who have not received ATT have died.

The immunosuppressant may aggravate mycobacterial infection [12]. The issue of corticosteroids, immunosuppressants and intravenous immunoglobulins in combination with tuberculosis treatment is therefore debated. According to the HAS [13], the treatment of HLH associated with an infectious cause is not the subject of recommendation of intravenous immunoglobulin because the evidence is missing, but this treatment is sometimes practiced with some successes registered [5].

The prognosis is maintained with a mortality rate of $49 \%$ [7, 14]. It also depends on the underlying disease, the speed of management and the treatment regimen [14]. If HLH is linked to tuberculosis, the prognosis is unfortunate with a mortality rate of 50\% [7]. Other poor prognostic factors are age over 30 years, hyperferritinemia, disseminated intravascular coagulation and high levels of beta-2microglobulin.

\section{Conclusion:-}

Tuberculosis, being a chronic disease, remains a common health problem in underdeveloped countries, with significant morbidity and mortality. In the disseminated form, it may be complicated by HLH, which may be diagnostically challenging to the treating physicians and in the absence of early therapy may lead to considerable morbidity and mortality.

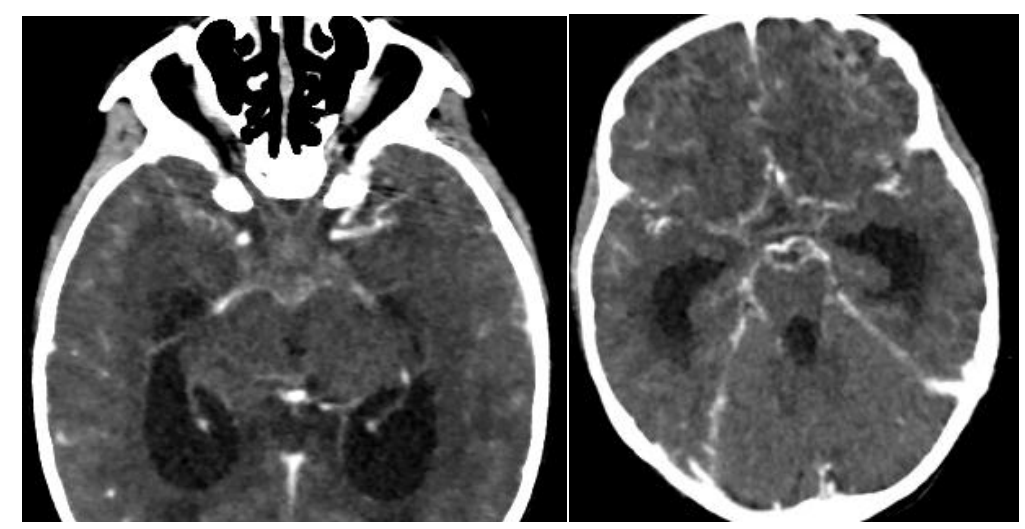

Figure 1:-Cerebral CT showing hydrocephalus with basal meningeal enhancement 


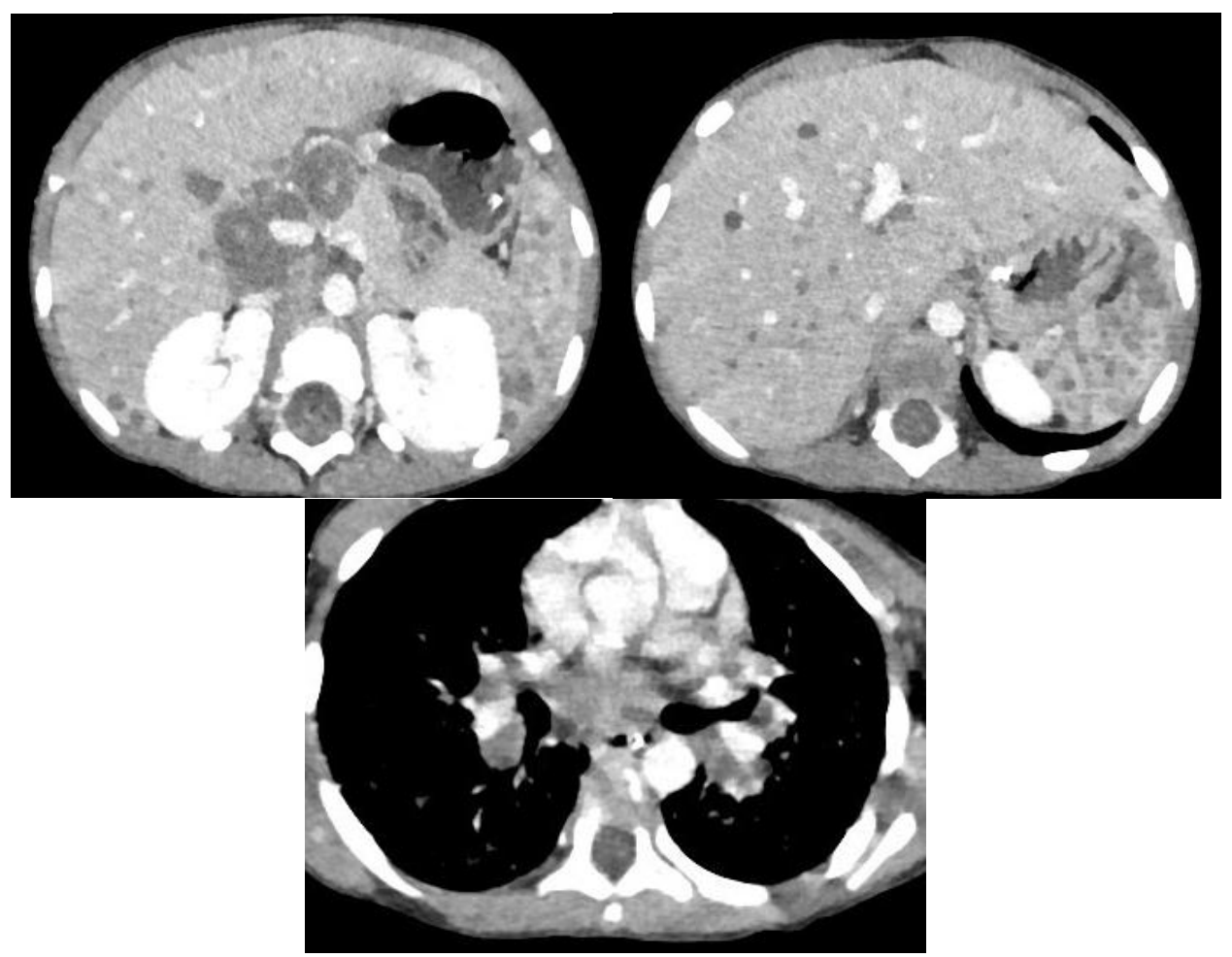

Figure 2:-Thoraco-abdominal CT showing a multiple mediastinal and abdominal adenopathies with necrotic centers associated to a hepatosplenomegaly containing hypodense nodules.

\section{References:-}

1. Zemed N, Khatib S,Oualil H,Bourkadi J.E(2016): Secondary hemophagocyticlymphohistiocytosis related to hematopoietic tuberculosis. Egyptian Journal of Chest Diseases and Tuberculosis. 65, 365-367

2. Gupta S, Weitzman S (2010): Primary and secondary hemophagocyticlymphohistiocytosis: Clinical features, pathogenesis and therapy. Expert Rev ClinImmunol. 6:137-54.

3. Rouphael NG, Talati NJ, Vaughan C, Cunningham K, Moreira R, Gould C(2007): Infections associated with hemophagocytic syndrome. Lancet Infect Dis. 7:814-22.

4. Brastianos PK, Swanson JW, Torbenson M, Sperati J, Karakousis PC (2006):Tuberculosis-associated hemophagocytic syndrome. Lancet Infect Dis 6:447-54.

5. Larroche $\mathrm{C}(2012)$ :Hemophagocyticlymphohistiocytosis in adults: diagnosis and treatment, Joint Bone Spine 79 (4):356-361.

6. Filipovich A.H(2009):Hemophagocyticlymphohistiocytosis (HLH) and related disorders, Hematol. Am. Soc. Hematol. Educ. Program. 127-131.

7. Ramos-Casals M, Brito-Zeron P, Lopez-Guillermo A, Khamashta M.A, Bosch X (2013) :Adult haemophagocytic syndrome, Lancet 26.

8. Le Hô H, Barbarot N, Desrues B (2010): Pancytopenia in disseminated tuberculosis: Think of macrophage activation syndrome. Revue des Maladies Respiratoires. 27, 257-260

9. Henter JI, Horne A, Aricó M, Egeler RM, Filipovich AH, Imashuku S, et al (2007): HLH-2004: Diagnostic and therapeutic guidelines for hemophagocyticlymphohistiocytosis. Pediatr Blood Cancer. 48:124-31.

10. Morrell D.S, Pepping M.A, Scott J.P, et al (2002): Cutaneous manifestations of hemophagocyticlymphohistiocytosis, Arch. Dermatol. 138 (9); 1208-1212.

11. Karras A, Hermine O (2002):Hemophagocytic syndrome, Rev Med Interne. 23 (9); 768-778.

12. Sandrini J, Beucher A.B, Rousselet M.C, Gardembas M, Lavigne C (2010):Tuberculosis with a hemophagocyticsyndrome, Med Mal Infect 40 (8); 476-479.

13. Afssaps (2009) : Recommandations de bon usage des immunoglobulines IV.

14. Roca F, Lesourd A, Chassagne $\mathrm{P}(2012)$ :A disseminated tuberculosis revealed by haemophagocytic syndrome, Eur. Geriatr. Med. 3; 382-383. 